Wright State University

CORE Scholar

\title{
Trends in Management of Overweight and Obesity in Obstetrics \& Gynecology, Family Medicine and Pediatrics 2011-2015
}

\author{
Steven Lindheim \\ Wright State University, steven.lindheim@wright.edu \\ Stephanie Welsh \\ Nan Jiang \\ Wright State University \\ Amanda Hawkins \\ Wright State University, amanda.hawkins@wright.edu \\ Lisa Kellar \\ Wright State University, lisa.kellar@wright.edu
}

See next page for additional authors

Follow this and additional works at: https://corescholar.libraries.wright.edu/obgyn

Part of the Obstetrics and Gynecology Commons

\section{Repository Citation}

Lindheim, S., Welsh, S., Jiang, N., Hawkins, A., Kellar, L., Maxwell, R., \& Whigham, L. D. (2017). Trends in Management of Overweight and Obesity in Obstetrics \& Gynecology, Family Medicine and Pediatrics 2011-2015. Journal of Obesity and Eating Disorders, 3 (1), 30.

https://corescholar.libraries.wright.edu/obgyn/22

This Article is brought to you for free and open access by the Obstetrics and Gynecology at CORE Scholar. It has been accepted for inclusion in Obstetrics and Gynecology Faculty Publications by an authorized administrator of CORE Scholar. For more information, please contact library-corescholar@wright.edu. 


\section{Authors}

Steven Lindheim, Stephanie Welsh, Nan Jiang, Amanda Hawkins, Lisa Kellar, Rose Maxwell, and Leah D. Whigham

This article is available at CORE Scholar: https://corescholar.libraries.wright.edu/obgyn/22 


\title{
Trends in Management of Overweight and Obesity in Obstetrics \& Gynecology, Family Medicine and Pediatrics 2011-2015
}

\author{
Steven R Lindheim ${ }^{1 *}$, Stephanie Welsh ${ }^{1}$, Nan Jiang $^{1}$, Amanda Hawkins ${ }^{1,2}$, Lisa Kellar1,3, Rose A. \\ Maxwell ${ }^{1}$ and Leah D. Whigham ${ }^{4}$
}

${ }^{1}$ Department of Obstetrics and Gynecology, Boonshoft School of Medicine, Wright State University, Dayton, Ohio, USA

${ }^{2}$ Wright Patterson US Air Force Center, Dayton, Ohio, USA

${ }^{3}$ Department of Family Medicine, Boonshoft School of Medicine, Wright State University, Dayton, Ohio, USA

${ }^{4}$ Paso de Norte Institute for Healthy Living, University of Texas at El Paso, El Paso, Texas, USA

*Corresponding author: Steven R. Lindheim, Department of Obstetrics and Gynecology, Boonshoft School of Medicine, Wright State University, USA, Tel: 937-208-2850; E-mail: steven.lindheim@wright.edu

Received date: April 24, 2017; Accepted date: May 22, 2017; Published date: May 30, 2017

Citation: Lindheim SR, Welsh S, J iang N, Hawkins A, Kellar L, et a I. ( 2017) Trends in Management of Overweight a nd O besity in Obstetrics \& Gynecology, Family Medicine and Pediatrics 2011-2015. J Obes Eat Disord 3:1. doi: 10.21767/2471-8203.100030

Copyright: (C) 2017 Lindheim SR, et al. This is an open-access article distributed under the terms of the Creative Commons Attribution License, which permits unrestricted use, distribution, and reproduction in any medium, provided the original author and source are credited.

\section{Abstract}

Purpose: To assess for improvement in the screening and management of overweight and obesity in the past 5 years among Obstetrician-Gynecologists (OB-GYN), Family Physicians (FP), and Pediatricians (Peds).

Methods: A retrospective pilot study was conducted, reviewing 150 charts of patients with overweight (body mass index [BMI] 25-29.9 kg/m²) and class I (BMI 30-34.9 $\left.\mathrm{kg} / \mathrm{m}^{2}\right)$, class II (BMI $\left.35-39.9 \mathrm{~kg} / \mathrm{m}^{2}\right)$, and class III obesity $\left(\mathrm{BMI} \geq 40 \mathrm{~kg} / \mathrm{m}^{2}\right.$ ) between 2011 and 2015. Patients were from OB-GYN $(n=50)$, Family Medicine, adult (FP-A) $(n=50)$ and pediatric (FP-P) $(n=28)$, and Peds $(n=22)$ offices.

Results: $75 \%$ of patients were female; $35.5 \%$ had overweight, $40 \%$ had class I obesity, $13.3 \%$ had class II obesity, and $11.3 \%$ had class III obesity. $100 \%$ of clinicians used BMI; none used waist circumference. Peds (91\%) and FP-P (96\%) visits were more likely to include counseling compared to OB-GYN (30\%) and FP-A (30\%) visits $(p<0.001)$. A decrease in nutrition counseling $(71 \%$ vs. 29\%, p<0.05) occurred between 2011 and 2015.

Conclusions: There remains significant room for improvement among all providers. Peds and FP-Ps may be more sensitive to the need for managing obesity than OBGYNs and FP-As. More efforts are needed to combat the obesity epidemic, starting with accurately identifying and counseling patients with obesity.

Keywords: Obesity; Mass screening; Trends

\section{Introduction}

Obesity is the most common chronic disease in the United States and affects more than 600 million adults worldwide [1]. Over two-thirds of American adults are overweight (body mass index $[\mathrm{BMI}] \geq 25 \mathrm{~kg} / \mathrm{m}^{2}$ ), along with about $15 \%$ of children aged 2-19 (sex-specific BMI-for-age between the 85th and 94.9th percentile) $(2,3)$. Further, one-third of adults and $17 \%$ of children are obese $\left(\mathrm{BMI} \geq 30 \mathrm{~kg} / \mathrm{m}^{2}\right.$ in adults, and sex-specific BMI-for-age $\geq 95$ th percentile in children) $(2,3)$.

The health burden of pediatric obesity is concerning, particularly since children with obesity are less likely to have healthy BMIs as adults [4]. While adult obesity still exceeds childhood obesity in the US, the percent increase in childhood obesity has been greater than that among adults in the past few decades: the relative annual increase between 1971 and 2002 has been reported at $4 \%$ in children aged $10-17$ years and $1.4 \%$ in adults [5].

The health risks of overweight and obesity in adults are well established, including type II diabetes, hypertension, coronary artery disease, stroke, and some cancers [6]. Obesity in children carries similar risks, including type II diabetes, hypertension, and dyslipidemia [7]. Health risks specific to females with overweight and obesity include polycystic ovarian syndrome, anovulation, infertility, and endometrial cancer [6]. Obesity during pregnancy imparts risks to both mother and child, such as gestational diabetes, cesarean section and congenital anomalies [6]. Moreover, children of mothers with obesity have an increased risk of obesity in adult life and increased all-cause mortality [6].

Given the burden of disease incurred by overweight and obesity, national guidelines exist to aid clinicians in managing these conditions. As early as 1998 the National Heart, Lung, and Blood Institute had developed guidelines for categorizing patients by BMI, waist circumference and risk factors; assessing patient motivation to lose weight; and following a treatment 
algorithm including dietary counseling, physical activity, behavioral therapy, medication, and surgical therapies [8]. These guidelines were recently updated in 2013 by the American Heart Association Task Force on Practice Guidelines (AHA), the American College of Cardiology (ACC), and The Obesity Society (TOS), based on evidence from the National Heart, Lung, and Blood Institute $[9,10]$. The updated guidelines suggest that height, weight and BMI be measured in all adults annually, and in addition, for adults with overweight and obesity, waist circumference should be measured annually [9]. Patients with the cardiovascular risk factors of dyslipidemia and hypertension, in addition to overweight and obesity, should be counseled on comprehensive lifestyle interventions that incorporate reduced caloric intake and increased physical activity [9]. Pharmacotherapy should be considered in patients with $\mathrm{BMI} \geq$ 30 or $\mathrm{BMI} \geq 27$ with comorbidities [9]. Patients with a $\mathrm{BMI} \geq 40$ $\mathrm{kg} / \mathrm{m}^{2}$ or with $\mathrm{BMI} \geq 35 \mathrm{~kg} / \mathrm{m}^{2}$ and comorbidities who have not benefited from lifestyle modification with or without pharmacotherapy should be counseled about bariatric surgery and referred to a specialist [9]. The guidelines also highlight the need for primary care physicians to work closely with their patients to develop individualized care plans that incorporate referrals to professionals trained in nutrition and behavioral psychology [9].

Other national medical organizations have provided recommendations or statements to providers including the American Academy of Pediatrics (AAP), the American College of Obstetrics \& Gynecology (ACOG) and the American Academy of Family Physicians (AAFP) [11-17]. Each AAP publication promotes the use of sex-specific BMI percentile for age to screen for overweight and obesity after age 2 [11,15]. Physicians have been encouraged to monitor for excess weight gain relative to linear growth, to assess diet and activity levels, and to encourage healthy behaviors in all patients $[11,15]$. Based on the ACOG and AAFP recommendations, physicians have been advised to identify patients with overweight and obesity using height, weight, and BMI, and to counsel them about dietary modification and physical activity.

Despite these recommendations, studies suggest that only $25-50 \%$ of patients with overweight and obesity are identified and counseled by their physicians [18-21]. However, the majority of studies have relied on self-reported data from physicians and patients, [20-26] and most of the existing literature contains data obtained prior to the release of the updated AHA/ACC/TOS guidelines in 2013 [20-23,27-30]. In our study, we examined trending data gathered from objective chart review to determine obesity identification and management before and after the updated guidelines were released.

\section{Methods}

This was a retrospective $c$ hart review study. T he $c$ harts of patients seen at three Midwestern academic practices, OB-GYN,
FP, and Peds, between January 1, 2011 and December 31, 2015 were reviewed. This study was undertaken with approval by the Wright State University Institutional Review Board

Charts were selected using a random number generator. Inclusion criteria included adults 18 years and older with a $\mathrm{BMI} \geq$ $25 \mathrm{~kg} / \mathrm{m}^{2}(\mathrm{n}=100)$ and children five years and older with a sexspecific weight-for-age $\geq 85^{\text {th }}$ percentile $(n=50)$. Weight-for-age was used in place of BMI-for-age because it was most commonly recorded in the Electronic Medical Records. When weight-forage was not recorded, it was calculated by the investigators. Pediatric measures of weight were adjusted for age and sex. Following inclusion, information was gathered from the first visit of the year and from all subsequent follow-up visits to the designated care center in that calendar year.

Information abstracted from the charts included demographics (sex, age, race), anthropometric parameters (height, weight, BMI, waist circumference, waist-to-hip ratio), diagnostic and screening information (diabetic screening, metabolic panel, lipid panel, endocrine screening), and information about counseling and referrals. Screening for diabetes was defined as performance of any of the following: blood glucose, hemoglobin $\mathrm{A} 1 \mathrm{C}$, and/or glucose tolerance testing. Endocrine screening was defined as lab testing for thyroid stimulating hormone, follicle stimulating hormone or luteinizing hormone. Counseling was defined as a documented discussion about weight, nutrition, pharmacologic therapy, and/or bariatric surgery. Referrals were defined as a referral to a nutritionist or registered dietitian, psychological counselor, or a bariatric surgeon.

Statistical analysis was performed using IBM SPSS statistical package 24. Chi-square analysis, t-test, and ANOVA were used as appropriate with a significance level of $\alpha<0.05$.

\section{Results}

\section{Demographics}

Seventy-five percent $(n=113)$ of charts reviewed were from female patients. The average age was $41.5 \pm 16.4$ years for adults, and $10.9 \pm 3.8$ years for children. Of adult patients $(n=100), 45 \%(n=45)$ had BMI $25-29.9 \mathrm{~kg} / \mathrm{m}^{2}, 18 \%(\mathrm{n}=18)$ had BMI $30-34.9 \mathrm{~kg} / \mathrm{m}^{2}, 20 \%(\mathrm{n}=20)$ had BMI $35-39.9 \mathrm{~kg} / \mathrm{m}^{2}$, and $17 \%(n=17)$ had BMI $\geq 40 \mathrm{~kg} / \mathrm{m}^{2}$. In pediatric patients $(n=50)$, $16 \%(n=8)$ had a weight-for-age between the $85^{\text {th }}$ and $94.9^{\text {th }}$ percentile and $84 \%(n=42)$ had a weight-for-age at or above the $95^{\text {th }}$ percentile. Ethnic distribution of all 150 participants included Caucasian (47\%, $n=70)$, African American (45\%, $n=68$ ), Hispanic $(4 \%, n=6)$, and other $(4 \%, n=6)$ (Table 1$)$.

Table 1: Patient Demographics by Medical Specialty (\%, (n)), Dayton, OH, 2011-2015, ap-values calculated using Chi square for sex, weight category, and race, and ANOVA for age, BMI, and weight-for-age; bNS, Not Significant; ${ }^{*}$ BMI $25-29.9 \mathrm{~kg} / \mathrm{m}^{2}$ for adults, weight-for-age percentile 
$85-94.9^{\text {th }}$ for children, ${ }^{* *} \mathrm{BMI} 30-34.9 \mathrm{~kg} / \mathrm{m}^{2}$ for adults, weight-for-age percentile $\geq 95^{\text {th }}$ for children, ${ }^{* * *} \mathrm{BMI} 35-39.9 \mathrm{~kg} / \mathrm{m}^{2},{ }^{* * * *} \mathrm{BMI} \geq$ $40 \mathrm{~kg} / \mathrm{m}^{2}$.

\begin{tabular}{|c|c|c|c|c|c|c|}
\hline \multirow[t]{2}{*}{ Variable } & Total & OB-GYN & FP-A & Peds & FP-P & \multirow[t]{2}{*}{ p-value ${ }^{a}$} \\
\hline & $(\mathrm{N}=150)$ & $(n=50)$ & $(n=50)$ & $(n=22)$ & $(n=28)$ & \\
\hline Female & $75 \%(113)$ & $100 \%(50)$ & $64 \%(32)$ & $50 \%(11)$ & $71 \%(20)$ & \multirow[t]{2}{*}{$p<0.001$} \\
\hline Male & $25 \%(37)$ & $0 \%(0)$ & $36 \%(18)$ & $50 \%(11)$ & $29 \%(8)$ & \\
\hline Age (years) & $31 \pm 19.8$ & $39 \pm 17.5$ & $44 \pm 14.8$ & $10 \pm 3.7$ & $12 \pm 3.8$ & $p<0.001$ \\
\hline BMI (kg/m2) & $34 \pm 14.5$ & $33 \pm 7.2$ & $33 \pm 6.4$ & $40 \pm 34.3$ & $32 \pm 6.0$ & $N S^{b}$ \\
\hline Weight-for-age percentile & $\mathrm{N} / \mathrm{A}$ & $\mathrm{N} / \mathrm{A}$ & $\mathrm{N} / \mathrm{A}$ & $98 \pm 4.0$ & 3.74E-195 & $p<0.001$ \\
\hline Overweight* & $35.3 \%(53)$ & $48 \%(24)$ & $42 \%(21)$ & $18 \%(4)$ & $14 \%(4)$ & \multirow[t]{4}{*}{ NS } \\
\hline Class I Obesity** & $40 \%(60)$ & $12 \%(6)$ & $24 \%(12)$ & $82 \%(18)$ & $86 \%(24)$ & \\
\hline Class II Obesity*** & $13.3 \%(20)$ & $22 \%(11)$ & $18 \%(9)$ & $\mathrm{N} / \mathrm{A}$ & N/A & \\
\hline Class III Obesity**** & $11.3 \%(17)$ & $18 \%(9)$ & $16 \%(8)$ & $\mathrm{N} / \mathrm{A}$ & N/A & \\
\hline Caucasian & $47 \%(70)$ & $75 \%(38)$ & $38 \%(19)$ & $45 \%(10)$ & $11 \%(3)$ & \multirow[t]{4}{*}{$p<0.001$} \\
\hline African-American & $45 \%(68)$ & $18 \%(9)$ & $56 \%(28)$ & $50 \%(11)$ & $71 \%(20)$ & \\
\hline Hispanic & $4 \%(6)$ & $2 \%(1)$ & $4 \%(2)$ & $5 \%(1)$ & $7 \%(2)$ & \\
\hline Other & $4 \%(6)$ & $4 \%(2)$ & $2 \%(1)$ & $0 \%(0)$ & $11 \%(3)$ & \\
\hline
\end{tabular}

\section{Screening, counseling and referral}

All patient charts $(n=150)$ had a BMI recorded, and $90 \%$ $(n=45)$ of children's charts also recorded weight-for-age percentiles. No providers recorded waist-to-hip ratio or waist circumference. Other screening and diagnostic tools for obesity and related conditions were measured inconsistently. Overall rates for diagnostic testing were $27 \%$ for metabolic panels, $33 \%$ for diabetic screens, $36 \%$ for lipid panels, and $29 \%$ for endocrine screens. Rates varied significantly between specialties for metabolic and lipid panels. FPs were more likely to order metabolic panels for both their adult $(42 \%, n=21)$ and pediatric $(39 \%, n=11)$ patients with overweight and obesity $(p<0.001)$ OB-GYNs were less likely than the three other specialties to order lipid panels $(\mathrm{p}<0.001)$ (Table 2$)$.

Table 2: Prevalence of Obesity-Related Testing by Medical Specialty, (\%, (n)), Dayton, OH, 2011-2015, aNS, Not Significant.

\begin{tabular}{|l|l|l|l|l|l|}
\hline Type of Testing & Overall & OB-GYN & FP-A & Peds & FP-P \\
\hline Metabolic panel & $27 \%(40)$ & $14 \%(7)$ & $42 \%(21)$ & $5 \%(1)$ & $39 \%(11)$ \\
\hline Diabetic screen & $33 \%(50)$ & $30 \%(15)$ & $32 \%(16)$ & $46 \%(10)$ & $32 \%(9)$ \\
\hline Lipid panel & $43 \%(64)$ & $10 \%(5)$ & $64 \%(32)$ & $55 \%(12)$ & $54 \%(15)$ \\
\hline Endocrine screen & $29 \%(43)$ & $20 \%(10)$ & $32 \%(16)$ & $34 \%(7)$ & $36 \%(10)$ \\
\hline
\end{tabular}

Table 3: Prevalence of Weight-Related Counseling by Medical Specialty (\%, (n)), Dayton, OH, 2011-2015, aNS, Not Significant.

\begin{tabular}{|c|c|c|c|c|c|c|}
\hline \multirow{2}{*}{ Nature of Counseling } & \multirow{2}{*}{ Overall } & \multirow{2}{*}{ OB-GYN } & \multirow{2}{*}{ FP-A } & \multirow{2}{*}{ Peds } & \multirow{2}{*}{ FP-P } & Chi-square \\
\hline & & & & & & $p$-value \\
\hline Discuss Weight & $51 \%(77)$ & $30 \%(15)$ & $30 \%(15)$ & $91 \%(20)$ & $96 \%(27)$ & $p<0.001$ \\
\hline Discuss Diet & $49 \%(73)$ & $24 \%(12)$ & $32 \%(16)$ & $86 \%(19)$ & $93 \%(26)$ & $p<0.001$ \\
\hline Discuss Medical Rx & $1 \%(2)$ & $2 \%(1)$ & $2 \%(1)$ & $0 \%(0)$ & $0 \%(0)$ & $\mathrm{NS}^{\mathrm{a}}$ \\
\hline Discuss Surgery & $<1 \%(1)$ & $0 \%(0)$ & $2 \%(1)$ & $0 \%(0)$ & $0 \%(0)$ & NS \\
\hline
\end{tabular}

Table 4: Prevalence of Obesity-Related Referral Practices by Specialty $(\%,(n))$, Dayton, $\mathrm{OH}, 2011-2015,{ }^{a} N S$, Not Significant.
OB-
GYN 


\begin{tabular}{|l|l|l|l|l|l|}
\hline & & & & p-value \\
\hline Nutritionist/ & $0 \%(0)$ & $14 \%(7)$ & $\begin{array}{l}18 \% \\
(4)\end{array}$ & $\begin{array}{l}21 \% \\
(6)\end{array}$ & $p<0.02$ \\
\cline { 1 - 5 } Dietitian & $2 \%(1)$ & $10 \%(5)$ & $\begin{array}{l}14 \% \\
(3)\end{array}$ & $\begin{array}{l}11 \% \\
(3)\end{array}$ & NSa \\
\hline Psychologist & $2 \%(1)$ & $0 \%(0)$ & $\begin{array}{l}0 \% \\
(0)\end{array}$ & $\begin{array}{l}0 \% \\
(0)\end{array}$ & NS \\
\hline Bariatric surgeon & & & & \\
\hline
\end{tabular}

Providers of all specialties provided counseling regarding weight loss $(51 \%, n=77)$ and nutrition $(49 \%, n=72)$ more often than regarding medical treatment $(1 \%, n=2)$ or surgical therapy $(<1 \%, n=1)$. Peds $(91 \%, n=20)$ and FP-P $(97 \%, n=27)$ visits were more likely to include discussion on weight issues compared to OB-GYNs $(30 \% n=15)$ and FP-A $(30 \%, n=15)$ visits $(p<0.001)$. Peds $(86 \%, n=19)$ and FP-P $(93 \%, n=26)$ visits were also more likely to include nutritional counseling compared to OB-GYNs $(24 \%, n=12)$ and FP-As $(32 \%, n=16)(p<0.001)$. In contrast, there were no differences in discussion of medication or surgery between specialties. Of adult patients with $\mathrm{BMI} \geq 40 \mathrm{~kg} / \mathrm{m}^{2}(\mathrm{n}=17)$, only $6 \%(n=1)$ had a discussion of bariatric surgery. Of all adult patients $(n=100)$, only $2 \% \quad(n=2)$ had a discussion of pharmaceutical therapy. Consistent with guidelines, there was no counseling with respect to medication use or bariatric surgery with pediatric patients (Table 3 ).
Nutritionist or dietitian referrals $(11 \%, n=17)$ were more common than referrals to psychological therapists $(8 \%, n=12)$ and bariatric surgeons $(<1 \%, n=1)$ among all specialties $(n=150)$. FP-Ps $(21 \%, n=6)$, Peds $(18 \%, n=4)$, FP-As $(14 \%, n=7)$ were significantly more likely than OB-GYNs $(0 \%)$ to refer their patients to a nutritionist or dietitian $(p<0.02)$. There were no significant differences between specialties in referral to psychological therapist or bariatric surgeon. As expected, no pediatric-aged patients were referred to a bariatric surgeon (Table 4).

\section{Trends over time}

Based on the selection of patients from the random number generator, charts were collected from $2011(n=21), 2012(n=9)$, $2013(n=75), 2014(n=28)$ and $2015(n=17)$. During the years studied, there was no improvement in any of the parameters evaluated across all specialties studied over the five-year period (Table 5). The only statistically significant changes were declines in the overall study prevalence of endocrine screens $(38 \%$ in 2011 vs. $12 \%$ in 2015$)(p<0.05)$ and diet discussions $(71 \%$ in 2011 vs. $29 \%$ in 2015$)(p<0.05)$.

Table 5: Obesity Screening and Management Trends (n, (\%)), Dayton, OH, 2011-2015, aNS, Not Significant.

\begin{tabular}{|c|c|c|c|c|c|c|}
\hline \multirow{2}{*}{ Variable } & 2011 & 2012 & 2013 & 2014 & 2015 & \multirow{2}{*}{$\begin{array}{l}\text { Chi square p- } \\
\text { value }\end{array}$} \\
\hline & $(n=21)$ & $(n=9)$ & $(n=75)$ & $(n=28)$ & $(n=17)$ & \\
\hline Metabolic panel & $5(24 \%)$ & $0(0 \%)$ & $20(27 \%)$ & $10(36 \%)$ & $5(29 \%)$ & $N^{a}$ \\
\hline Diabetic screen & $10(48 \%)$ & $1(11 \%)$ & $22(29 \%)$ & $11(39 \%)$ & $6(35 \%)$ & NS \\
\hline Lipid panel & $8(38 \%)$ & $1(11 \%)$ & $38(51 \%)$ & $12(43 \%)$ & $5(29 \%)$ & NS \\
\hline Endocrine screen & $8(38 \%)$ & $0(0 \%)$ & $27(36 \%)$ & $6(21 \%)$ & $2(12 \%)$ & $p<0.05$ \\
\hline Discuss weight & $15(71 \%)$ & $3(33 \%)$ & $42(56 \%)$ & $12(43 \%)$ & $5(29 \%)$ & NS \\
\hline Discuss diet & $15(71 \%)$ & $3(33 \%)$ & $40(53 \%)$ & $10(36 \%)$ & $5(29 \%)$ & $p<0.05$ \\
\hline Discuss medication & $0(0 \%)$ & $1(11 \%)$ & $0(0 \%)$ & $1(4 \%)$ & $0(0 \%)$ & NS \\
\hline Discuss surgery & $1(5 \%)$ & $0(0 \%)$ & $0(0 \%)$ & $0(0 \%)$ & $0(0 \%)$ & NS \\
\hline Referral to nutrition & $4(19 \%)$ & $0(0 \%)$ & $9(12 \%)$ & $3(11 \%)$ & $1(6 \%)$ & NS \\
\hline Referral to psych & $1(5 \%)$ & $0(0 \%)$ & $8(11 \%)$ & $2(7 \%)$ & $1(6 \%)$ & NS \\
\hline Referral to bariatric surgeon & $0(0 \%)$ & $0(0 \%)$ & $0(0 \%)$ & $1(4 \%)$ & $0(0 \%)$ & NS \\
\hline
\end{tabular}

\section{Discussion}

Our findings suggest that overall there was no observed improvement over time in physician practices related to addressing overweight and obesity with patients. Physicians caring for pediatric patients were more likely to provide weight and nutritional counseling than physicians caring for adult patients. Furthermore, Peds, FP-P and FP-A were each more likely to refer patients to a nutritionist or dietitian than OB-GYN.
Obesity screening and management practices have been widely studied among Peds. A 2009 survey of Peds revealed that fewer than half of clinicians identified and managed obesity correctly: $46 \%$ of physicians reported calculating patient BMI routinely, and $31 \%$ knew the definitions for pediatric overweight and obesity [19]. Another study revealed that Peds identified obesity $53 \%$ of the time, however when obesity was identified, $71 \%$ provided nutritional counseling and only $22 \%$ referred to a dietitian [27]. The authors reported that identification of children with excess weight was perhaps related to the degree of overweight, as Peds recognized only $27 \%$ of children with 
overweight compared to $86 \%$ of children with obesity [28]. A more recent 2015 study revealed a lack of improvement, with documentation of obesity $34 \%$ of the time, and appropriate dietary recommendations given $11 \%$ of the time [31].

Screening for complications of obesity is also an integral part of management, though recent studies show sub-optimal screening practices. Twenty-two percent of patients with obesity were screened for diabetes, liver, and lipid abnormalities; $52 \%$ were screened for only glucose abnormalities; $30 \%$ for only liver abnormalities; and $41 \%$ for only lipid abnormalities [29]. Other studies revealed that just $4 \%$ were screened for diabetes, $9 \%$ for lipid abnormalities, and $2 \%$ for liver abnormalities [30,32].

With respect to obesity screening and management by providers of adult patients, obesity was detected in $38 \%$ of patients and appropriate counseling was provided to less than $25 \%$ of patients, according to a national $1995-1996$ survey [20]. A 2008 study of primary care providers showed that overall, 49\% reported measuring BMI regularly; fewer than $50 \%$ provided weight, diet, or exercise counseling; and fewer than $10 \%$ referred their patients to nutritionists or other providers [21]. FP-As were most likely to report measuring BMI regularly compared to other adult specialties [21]. OB-GYNs and FPs were both less likely than internists to provide weight counseling to their patients with chronic disease [21]. OB-GYNs were also more likely than FPs and internists to report never having assessed their patients' diet or exercise habits [21].

Other studies report that while $100 \%$ of surveyed physicians state that they discuss weight management with their patients with overweight and obesity, just over half of these patients reported having such a discussion with their doctor [18] Physicians fail to initiate weight loss conversations for a variety of reasons. Some physicians feel ill equipped to advise their patients on weight loss, either from a lack of training or a lack of access to nutritionists or other specialists for referral [33]. Moreover, some physicians feel pessimistic about their patients' motivation or ability to lose weight [22].

Given the increasing awareness of obesity and the widespread promotion of the 2013 AHA/ACC/TOS guidelines, an improvement in management practices was expected. However, our findings did not support this hypothesis. Furthermore, our findings revealed a decline in a few management trends over 2011-2015, which is in conflict with a study from 1999-2008, which found an increase in parents reporting that they were told their child's overweight or obese status by their pediatric provider [23].

At the practices studied, auxiliary staff measure patient height and weight, and BMI is automatically calculated in the Electronic Medical Record, making BMI a convenient tool for obesity screening. However, central adiposity is more highly correlated with cardiovascular risk factors than peripheral adiposity, and this distinction can be overlooked by BMI. Waist circumference is a more reliable indicator of central adiposity, but measurements vary with patient posture, respiration, abdominal wall tension, and stomach contents, making this method more difficult for providers [34]. More education and standardized procedures may be needed to make alternative measures of obesity more feasible to collect.

We attempted to objectively collect data from physician charts, providing a more accurate picture of practices than selfreported studies. Furthermore, we compared physician practices among several different specialties, again lending more credibility than single-specialty studies. However, we recognize that our study is limited by a small sample size, with potential limits in the generalizability of our results. Also, there was significant variability in the number of charts reviewed per year, which may have adversely affected our trends analysis. Another limitation is that it is also possible that discussions regarding obesity management, diet, exercise, etc., were not documented in the chart. In spite of these limitations, this study suggests that overweight and obesity management is lacking despite recently updated guidelines. Indications for future research include larger-scale studies of physician practices across specialties to assess how obesity management compares across larger populations.

\section{Conclusion}

Screening for and treatment of obesity by physicians is an important aspect of curbing the obesity epidemic. Weight counseling and pharmacotherapy are proven to produce modest weight loss (3-5 kg) and improved health outcomes, while bariatric surgery produces more dramatic weight loss (10-15 kg) [35]. Particularly for pediatric patients, preventing childhood obesity is imperative since children with obesity are more likely to become adults with obesity $[36,37]$. While national guidelines provide an effective screening and intervention tool for overweight and obesity management, our findings suggest that there remains significant room for improvement, particularly in providers caring for adult patients. Peds and FP-Ps may be more sensitive to the need for managing obesity than OB-GYNs and FP-As, and the other disciplines could learn from these findings.

\section{References}

1. World Health Organization (2015) Obesity and overweight Fact sheet $\mathrm{N}^{\circ} 311$.

2. Ogden CL, Carroll MD, Kit BK, Flegal KM (2014) Prevalence of Childhood and Adult Obesity in the United States, 2011-2012. JAMA 311: 806-814.

3. Kopelman P (2007) Health risks associated with overweight and obesity. Obes Rev 8: 13-17.

4. Serdula MK, Ivery D, Coates RJ, Freedman DS, Williamson DF, et al. (1993) Do obese children become obese adults? A review of the literature. Prev Med 22: 167-177.

5. Popkin BM, Conde W, Hou N, Monteiro C (2006) Is There a Lag Globally in Overweight Trends for Children Compared with Adults?. Obesity 14: 1846-1853.

6. Ethical issues in the care of the obese woman. Committee Opinion No. 600. American College of Obstetricians and Gynecologists. Obstet Gynecol 2014; 123: 1388-1393.

7. Ebbeling CB, Pawlak DB, Ludwig D (2000) Childhood obesity: public-health crisis, common sense cure. Lancet 360: 473-482. 
8. National Institutes of Health (1998) Clinical Guidelines on the Identification, Evaluation, and Treatment of Overweight and Obesity in Adults-The Evidence Report. Obes Res 6: 51S-209S.

9. Jensen MD, Ryan DH, Apovian CM (2014) 2013 AHA/ACC/TOS guideline for the management of overweight and obesity in adults: a report of the American College of Cardiology/American Heart Association Task Force on Practice Guidelines and The Obesity Society. J Am Coll Cardiol 63: 2985-3023.

10. "Managing Overweight and Obesity in Adults: Systematic Evidence Review from the Obesity Expert Panel", Systematic Evidence Review From the Obesity Expert Panel 2013, US Department of Health and Human Services, National Heart, Lung, and Blood Institute, 2013.

11. American Academy of Pediatrics. Policy Statement: Prevention of Pediatric Overweight and Obesity. J Pediatr 2003; 112: 424-430.

12. ACOG Committee Opinion No. 470: Challenges for overweight and obese urban women. Obstet Gynecol 116: 1011-1014.

13. Rao G (2010) Office-Based Strategies for the Management of Obesity. Am Fam Physician 81: 1449-1455.

14. American Academy of Pediatrics. AAP publications retired or reaffirmed, October 2006. J Pediatr 119: 405-620.

15. Daniels SR, Hassink SG (2015) COMMITTEE ON NUTRITION. The Role of the Pediatrician in Primary Prevention of Obesity. J Pediatr 136: e275.

16. ACOG Committee Opinion No. 591: Challenges for overweight and obese urban women. Obstet Gynecol 123: 726-730.

17. Erlandson M, Ivey LC, Seikel K. (2016) Updated on Office-Based Strategies for the Management of Obesity. Am Fam Physician 94: 361-368.

18. Whiteman H. Patient-doctor disconnect 'impacts weight loss interventions'. Medical News Today.

19. Huang JS, Donohue M, Golnari G, Fernandez S, Walker-Gallego E, et al. (2009) Pediatricians' weight assessment and obesity management practices. BMC Pediatr 9: 19-45.

20. Stafford RS, Farhat JH, Misra B, Schoenfield DA (2000) National Patterns of Physician Activities Related to Obesity Management. Arch Fam Med 9: 631-638.

21. Smith AW, Borowski LA, Liu B (2011) US Primary Care Physicians Diet, Physical Activity, and Weight-Related Care of Adult Patients. Am J Prev Med 41: 33-42.

22. Kottke TE, Foels JK, Hill C, Choi T, Fenderson DA (1984) Nutrition counseling in private practice: attitudes and activities of family physicians. Prev Med 13: 219-225.

23. Perrin EM, Skinner AC, Steiner MJ (2012) Parental recall of doctor communication of weight status: national trends from 1999 through 2008. Arch Pediatr Adolesc Med 166: 317-322.
24. Petrin C, Kahan S, Turner M, Gallagher C, Dietz WH (2016) Current practices of obesity pharmacotherapy, bariatric surgery referral and coding for counselling by healthcare professionals. Obes Sci \& Prac 2: 266-271.

25. Morris GL, Chapman K, Nelson D, Fink J, Walker R, et al. (2016) Physician use of electronic health records in obesity management. Wis Med J 115: 140-142.

26. Petrin C, Kahan S, Turner M, Gallagher C, Dietz WH,et al. (2016) Current attitudes and practices of obesity counseling by health care providers. Obes Res Clin Pract 11: 352-359.

27. O'Brien SH, Holubkov R, Reis EC (2004) Identification, evaluation, and management of obesity in an academic primary care center. J Pediatr 114: e154-159.

28. Barlow SE, Bobra SR, Elliott MB, Brownson RC, Haire-Joshu (2007) Recognition of childhood overweight during health supervision visits: Does BMI help pediatricians?. Obesity 15: 225-232.

29. Benson, LJ, Baer HJ, Kaelber DC (2011) Screening for ObesityRelated Complications Among Obese Children and Adolescents: 1999-2008. Obesity 19: 1077-1082.

30. Riley MR, Bass NM, Rosenthal P, Merriman RB (2005) Underdiagnosis of pediatric obesity and underscreening for fatty liver disease and metabolic syndrome by pediatricians and pediatric subspecialists. J Pediatr 147: 839-842.

31. Reyes I (2015) An evaluation of the identification and management of overweight and obesity in a pediatric clinic. J Pediatr Health Care 29: e9-e14.

32. Dilley KJ, Martin LA, Sullivan C, Seshadri R, Binns HJ, et al. (2007) Identification of overweight status is associated with higher rates of screening for comorbidities of overweight in pediatric primary care practice. J Pediatr 119: e148-e155.

33. Anderson CK, Walch TJ, Lindberg SM, Smith AM, Lindheim SR, et al. (2015) Excess gestational weight gain in low-income overweight and obese women: a qualitative study. J Nutr Educ Behav 47: 404-411.

34. World Health Organization (2011) Waist circumference and waisthip ratio: Report of a WHO expert consultation, Geneva, 8-11 December 2008.

35. McTigue KM, Harris R, Hemphill B (2003) Screening and Interventions for Obesity in Adults: Summary of the Evidence for the U.S. Preventive Services Task Force. Ann Intern Med 139: 933-949.

36. Guo SS, Chumlea WC (1999) Tracking of body mass index in children in relation to overweight in adulthood. Am J Clin Nutr 70: S145-S148.

37. Freedman DS, Kettel L, Serdula MK, Dietz WH, Srinivasan SR, et al. (2005) The relation of childhood BMI to adult adiposity: the Bogalusa Heart Study. J Pediatr 115: 22-27. 